\title{
COLONIAL EXPERIENCE AND THE THEORY OF COUNTER-GUERRILLA WARFARE IN THE USA: A SOURCE STUDY OF MATERIALS FROM THE RAND CORPORATION IN THE FIRST HALF OF THE 1960S
}

\author{
(C) 2018
}

Nesterov Dmitriy Aleksandrovich, master student of World History, Law and Methods of Teaching Department Samara State University of Social Sciences and Education (Samara, Russian Federation)

\begin{abstract}
This paper analyzes materials of the RAND Corporation of the first half of the 1960s, devoted to the study of the colonial experience of European empires and the theory of counter-guerrilla warfare. The entire set of documents created by the RAND Corporation allows researchers, firstly, to analyze the intellectual resource available to the American establishment before the invasion of Vietnam, and to understand the causes of the mistakes and successes of the US armed forces in this region, and secondly, these materials allow to analyze the role of colonial and anthropological knowledge in US foreign policy during the Cold War. The sources considered by us in the paper can be classified both by their typology and by their subject matter: from the point of view of typology, RAND Corporation's materials are divided into articles, memoranda and symposia materials, as well as from the point of view of subjects on the research of the war for Algeria, the Malay Company, counter-guerrilla warfare in Vietnam and general theoretical issues related to counter-insurgency operations. In the conclusion of the paper the author says about the great role of these sources in the study, both colonial experience and the theory of counter-guerrilla warfare, as well as military, political, social and economic, thus contributing to the interdisciplinarity of scientific papers.

Keywords: the United States in first half of the 1960s; Third World countries; decolonization; anti-insurgency; insurgents; partisans; historical source; RAND Corporation; Vietnam War; Algeria; Philippines; Malaya; Southeast Asia; resettlement programs; air force; colonial experience; theory of counter-guerrilla operations; asymmetric conflict.
\end{abstract}

УДК [93:130.2](470+571):94(5)(045)

Статья поступила в редакцию 07.04.2018

\section{Д.И. МЕНДЕЛЕЕВ О КУЛЬТУРНО-ИСТОРИЧЕСКИХ ЗАДАЧАХ РОССИИ НА ВОСТОКЕ}

(C) 2018

Суворов Валерий Владимирович, кандидат исторических наук, ассистент кафедры философии, гуманитарных наук и психологии Саратовский государственный медицинский университет имени В.И. Разумовского (2. Саратов, Российская Федераџия)

Аннотация. На рубеже XIX-XX веков движение России на Восток стало одной из обсуждаемых тем в отечественной публицистике и научной мысли. Свои взгляды по данному вопросу высказывал и выдающийся ученый Д.И. Менделеев. В своих работах он подчеркивал историческую необходимость и неизбежность выхода России к Тихому океану, важность развития дальневосточного направления ее внешней политики. Показывая культурно-цивилизационную дистанцированность России от Запада, он акцентировал внимание на наличии в ней восточных черт, но при этом отмечал ее культурно-историческую уникальность. В рассуждениях Менделеева прослеживается отход от европоцентризма в оценках Востока и России. Говоря о культурно-исторических задачах России, ученый подчеркивал большую важность поддержания «обаяния» ее имени на Востоке, чем подражания западным государствам, особенно Англии, в отношении ко всей Азии, в которой роль России должна была остаться «освободительной и просветительной». В работах Менделеева особый акцент делался на мирном укреплении России в Азии и дружелюбном отношении к восточным народам. Интересной особенностью рассуждений Менделеева является мотив сказки: с одной стороны, это полусказочный Восток, с другой - сказка как образ идеального будущего для России.

Ключевые слова: Дмитрий Иванович Менделеев; С.Ю. Витте; Российская империя; Западные страны; внешняя политика; культурно-исторические задачи России на Востоке; Азия; Дальний Восток; Тихий океан; КВЖД; «Заветные мысли»; «К познанию России»; Китай; Япония; Русско-японская война; восточные народы; евразийство.

На рубеже XIX-XX веков движение России на Восток стало одной из обсуждаемых тем в отечественной публицистике и научной мысли. Среди сторонников дальневосточной политики особенно выделялись С.Ю. Витте и Э.Э. Ухтомский, а также немногочисленные сторонники его взглядов [1-3]. При изучении отношения российской общественности к расширению России на Восток на рубеже XIX$\mathrm{XX}$ веков, формировании образов Востока, определению культурно-исторических задач России в Азии важно обратиться к взглядам выдающегося ученого Дмитрия Ивановича Менделеева, который еще в

1896 г. характеризовал всеобщий интерес в отношении к Азиатскому Востоку не модой, а «предвестием начала новейшей истории», начала новейшей истории, «в которой роль Средиземного моря - древности и Атлантического океана - новых времен займет не один Тихий океан, а все соленые воды, и круглота земного шара с единством всех людей станет живою реальностью» [4, с. 104]. Главным образом его отношение к вопросам движения России на Восток и ее культурно-исторических задач было представлено в последних его крупных работах «Заветные мысли» (1905 г.) и «К познанию России» 
(1906 г.). В книге «Заветные мысли», законченной в время Русско-японской войны, Менделеев говорит о возможных путях геополитического и экономического развития России.

Жизни, деятельности и особенно научным открытиям Д.И. Менделеева посвящено немало исследований [5; 6 и др.]. Однако его взгляды на геополитические и культурно-исторические особенности России попадают в поле зрения исследователей гораздо реже [7; 8; 9 и др.]. Среди исследователей особое внимание идейному наследию ученого уделяет И.А. Козиков, в работах которого нашли отражение различные вопросы, связанные с пониманием Менделеевым особенностей исторического развития России, ее социально-политических и экономических особенностей [10-13 и др.]. Ряд исследователей проводят аналогии между взглядами Менделеева и евразийством, находя между ними немало общих идей [14-16]. Таким образом, хотя исследователи и обращаются к идейному наследию Д.И. Менделеева, его отношению к расширению Российской империи на Восток, тем не менее как самостоятельная проблема понимание им культурно-исторических задач России в Азии не рассматривалась.

Получение выхода к Тихому океану всегда интересовало Д.И. Менделеева. Одним из предполагаемых путей был путь через Арктику, и ученый прилагал усилия, чтобы исследовать данный путь, о чем свидетельствует, например, его докладная записка С.Ю. Витте в 1901 г. [17, с. 99-100]. Сам Витте отмечал, что «делу открытия морского пути на Дальний Восток через сибирские прибрежья, а равно плаванию по направлению к полярному полюсу очень сочувствовал также известный наш ученый Менделеев» [18, с. 657]. В проникнутых патриотическими мотивами записках важное место занимал вопрос о расширении России на дальнем Востоке и ее выходе к Тихому Океану. Д.И. Менделеев акцентировал внимание на общем подъеме патриотизма, который наступил после начала Русско-японской войны [19, c. 205]. Объясняя причины такого подъема, он выделил инстинктивное стремление русского народа «из лесов и степей добраться до свободных теплых морей», а вся историческое развитие России было направлено к укреплению на морских берегах «как на местах наступившей истории человечества» [19, c. 208].

Выход к Тихому океану, по мысли ученого, имел особую значимость и масштабы. Завершение строительства КВЖД, в которой Менделеев видел «великое и чисто русское дело» [19, с. 213], обеспечило крепкое положение России «на теплом и открытом море». Устремление взоров российской общественности на Тихий океан, по его мнению, было обусловлено осознанием того, «дело здесь идет о чем-то очень существенном, что тут выполняется наяву давняя сказка» [19, с. 213]. Ученый подчеркивает, что за Тихоокеанским регионом «великое будущее», так как «полусказочном» азиатском побережье проживало намного больше людей, чем на берегах Средиземного, Черного и Балтийского морей и всего Атлантического океана [19, с. 213-214]. Д.И. Менделеев отмечал, что берега Тихого океана, выход к ко- торым получила Россия, дали путь для осуществления «родной сказки», к уравновешиванию «центробежной нашей силы с центростремительной», к будущей истории, которая «неизбежно станет совершаться на берегах и на водах Великого Океана» [19, c. 214].

Особое место в рассуждениях Д.И. Менделеева занимали китайцы. Он выделял такие особенности взаимоотношений с китайским народом, как дружественность и готовность оказать помощь «кичливым» китайцам, добродушие в отношении с ними $[19$, с. 218]. Ученый подчеркивал, что «едва ли какой другой народ в мире отдает столько справедливости, как мы, китайцам», так как «они сумели сохранить семейственную благодушность и миролюбивое следование за своими мудрецами при всех исторических передрягах, с ними бывших» [19, с. 218]. Менделеев настаивал на необходимости объективного отношения к находящимся под «маньчжурским игом» китайцам. В силу сложившихся стереотипов их неправильно понимали, считая по природе косным и принципиально одряхлевшим народом, так как судили о китайцах только по современному для того времени Китаю. Ученый отмечал, что не учитывались исторические достижения китайцев: раньше европейцев они изобрели бумагу и печать, были противниками войн и передовыми земледельцами, умеющими обходиться без аристократических привилегий, почитали мудрецов и ученых, изобрели и компас, и астрономические счисления, сумели сам по себе хлопок превратить в ткани, открыли искусство получать шелк из червяка, изобрели фарфор, дали всем людям чай, нашли порох [19, с. 218-219]. Современных для своего времени китайцев Менделеев характеризовал как в существе своем смирного, земледельчески трудолюбивого, торгового, промышленного и во всех отношениях весьма способного народа, только лишенного организационной способности и мало склонного к воинским приключениям [19, с. 219-220]. Д.И. Менделеев писал, что Китай, не знавший наследственного аристократизма, всегда был монархическим и сохранялся многие тысячелетия, в отличие от государств, имевших аристократов, которые всегда были «первыми между ворчунами, смутьянами, интриганами (от ничегонеделания и безответственной обеспеченности), даже не раз очень ловкими бунтарями» [19, с. 321]. Ученый сопоставлял некоторые особенности России и Китая. Россия, как Китай, была бедна, при своих природных богатства, поэтому первоочередной задачей правительств, по его мнению, было определение условий для «возможности и возбуждения в народе усиленного труда, накопления капиталов и возрастания богатства [19, с. 329]. По мнению Менделеева, китайцы в новейшей истории должны были проявить на мировой сцене, так как их влиятельная самобытность проявлялась в их чуждости воинственности и аристократизму, умении приручать завоевателей (монголов и маньчжуров), способности сохраняться тысячелетия, «как ни один другой народ». Подводя итог, ученый отмечал, что в них есть «нечто высшее, общее или социальное» [19, с. 246]. 
Отношение к японцам было совсем иным, так как, по мнению Менделеева, для русских коварство и японцы до некоторой степени сливались [19, с. 220]. Недовольство ими распространилось в России, когда японцы стали вмешиваться в отношения России к китайцам, маньчжурам и корейцам, а начало военных действий усилило «недоброе к ним чувство» [19, c. 220]. Даже если Россия когда-нибудь их и простила бы, писал Менделеев, то такого отношения, как к другим восточным народам, с которыми она соседствовала, уже никогда бы не возникло, так как они первые пошли на Россию, против ее естественных отношений к соседям по суше $[19$, с. 220]. К тому же, по мнению Менделеева, японцы в отличие от китайцев были лишены всякой оригинальности по существу, ничего не дали миру, хотя и умели ловко принимать заимствованные образцы [19, с. 220].

Говоря о «желтой угрозе», о возможности покорения Европы представителями желтой расы, высказанной еще В.С. Соловьевым, Д.И. Менделеев выступал с решительным опровержением возможности такого развития событий, а противоположение европейских и восточных народов он называл «тщедушной попыткой резонерства» [19, с. 214]. Определяя исторические задачи российского государства в случае победы в войне с Японией, Менделеев считал, России следовало бы кроме контрибуции ничего себе не брать, кроме того, что было накануне войны и что было нужно для выполнения исторических задач, часть которых лежала, по мнению ученого, в развитии нашего дальневосточного региона, прилегавшего к Тихому океану [19, с. 236]. Ученый подчеркивает важность поддержания «обаяния нашего имени» в большей мере, чем подражания «в каком бы то ни было виде англичанам», особенно в отношению ко всей Азии, в которой роль России должна была остаться «освободительной и просветительной» $[19$, c. 236].

Д.И. Менделеев отмечал одну важную особенность культурно-исторического развития России, заключавшуюся в том, что русские восприняли начало латиносаксонской цивилизации позднее других западноевропейцев, а потому сохранили больше, чем они, «некоторые начальные стороны азиатской жизни» $[19$, с. 246]. В самом начале книги «К познанию России» Менделеев также акцентировал внимание на культурно-исторических особенностях России: «Страна-то ведь наша особая, стоящая между молотом Европы и наковальней Азии, долженствующая так или иначе их примирить» $[20$, с. 3]. Подобные взгляды дают основание некоторые исследователям относить Менделеева к «представителям евразийства» $[15$, с. 124$]$. Менделеев отмечал, что такая культурная особенность России может послужить ей на благо, так как географически она занимала центральное положение между Западом и Востоком, а «сравнительно молодое Русское Царство» могло бы легко одолеть «труд объединения двух важнейших частей человечества» [19, с. 246]. Россия в силу своего «срединного» положения, «громадности» протяжения ее азиатских границ и текущей войны с Японией должна была принять большое участие в «готовящихся мировых событиях» [19, с. 246]. О «средин- ном положении» России между Европой и Азией на пути великого переселения народов Менделеев упоминал и в контексте многонациональности России. Так, став основным путем великого переселения народов, территория России содержала «осевшие на месте их остатки» [20, с. 33].

Д.И. Менделеев обращал внимание на миролюбивость русского народа и мирные способы расширения Российского государства: «Тот путь, которым Россия расширилась до громадной современной величины, особенно в Азии, определился больше всего тем, что почти без войн делали казаки, присоединяя к Русской державе земли маленьких народов, затем охотно сливавшихся с Россией, так как через это слияние их выгоды были, очевидно, большими, чем для покоряющей России» [19, с. 215]. Ученый отмечал пределы цивилизаторских возможностей Запада и культурно-историческую роль восточных народов. Все народы имели свои особенности, как культурные, так и антропологические, поэтому, сколько бы они ни воспринимали от общеевропейской цивилизации, все же остались бы со своими особенностями. Менделеев не сомневался, что именно эти народы внесут в мир много такого, что «отличит новейшую историю от новой в большей мере, чем эта последняя отличается от «средней»» [19, с. 245].

Таким образом, Д.И. Менделеев в своих работах подчеркивал историческую необходимость и неизбежность выхода России к Тихому океану и важность развития дальневосточного направления. Показывая культурно-цивилизационную дистанцированность России от Запада, он акцентировал внимание на наличии в ней восточных черт, но при этом отмечал ее культурно-историческую уникальность. Ученый подчеркивал большую важность поддержания «обаяния» имени России на Востоке, чем подражания западным государствам, особенно Англии, в отношении ко всей Азии, в которой роль России должна была остаться «освободительной и просветительной». В рассуждениях Менделеева прослеживается отход от европоцентризма в оценках Востока и России. Интересной особенностью рассуждений Менделеева является мотив сказки: с одной стороны, это полусказочный Восток, с другой - сказка как образ идеального будущего для России.

\section{Список литературы:}

1. Суворов В.В. «Восточничество»: культурно-историческая концепция и имперская идеология. Саратов: Изд-во Саратовского ГМУ им. В.И. Разумовского, 2015. $107 \mathrm{c}$.

2. Suvorov V.V. Views of S.Yu. Witte on the cultural and historical tasks of Russia in the East // Былые годы. Российский исторический журнал. 2017. № 45 (3). C. 1036-1043.

3. Суворов В.В. Культурно-исторические задачи России на востоке во взглядах С.Н. Сыромятникова // Самарский научный вестник. 2017. Т. 6, № 3 (20). С. 259-262.

4. Менделеев Д.И. Впечатление о всероссийской выставке в Нижнем Новгороде // Проблемы экономического развития России / Д.И. Менделеев. М.: 
Издательство социально-экономической литературы, 1960. C. $104-110$.

5. Чугаев Л.А. Дмитрий Иванович Менделеев. Биография русского гения // Экология и жизнь. 2009. № 1. С. 12-19.

6. Михайлов О.В. Легенды и были о Менделееве, русской водке и сверхкритических флюидах // Вестник Российской академии наук. 2013. Т. 83, № 4. C. $381-384$.

7. Гердт Я.В. Д.И. Менделеев о влиянии природных условий на историю, развитие и политику государства // Евразийский журнал региональных и политических исследований. 2007. № 23. С. 47-52.

8. Серёгин А.В. Монархические идеи Д.И. Менделеева // Право и государство: теория и практика. 2009. № 7. С. 105-107.

9. Егоров Г.В. Социально-гуманитарные взгляды Д.И. Менделеева // Вестник Нижегородского университета им. Н.И. Лобачевского. 2015. № 5-6. С. 41-45.

10. Козиков И.А. Российские естествоиспытатели о славянах (М.В. Ломоносов, Д.И. Менделеев, В.И. Вернадский) // Вестник Российской нации. 2009. Т. 5, № 3. С. 49-65.

11. Козиков И.А. Д.И. Менделеев об особенностях образования российского государства // Вестник Российской нации. 2011. Т. 17, № 3. С. 86-94.

12. Козиков И.А. Д.И. Менделеев о территориальной целостности России // Национальные интересы России: глобальные приоритеты, политические стратегии и перспективы: мат-лы Первого съезда Российского общества политологов. 2014. С. 614-620.
13. Козиков И.А. Великий завет Д.И. Менделеева // Вестник Российской нации. 2015. Т. 4, № 4-4 (42). C. $78-90$.

14. Гловели Г.Д. Д.И. Менделеев и евразийство // Философия хозяйства. 2009. № 2 (62). С. 252-265.

15. Козик И.А. Д.И. Менделеев и В.И. Вернадский о цивилизационных особенностях России // Проблемный анализ и государственно-управленческое проектирование. 2012. Т. 5. Вып. 6 (26). С. 123-131.

16. Исаева О.С. Об источниках геосоциологии классического евразийства // Известия высших учебных заведений. Поволжский регион. Общественные науки. 2015. С. 112-119.

17. Менделеев Д.И. Об исследовании Северного полярного океана // Проблемы экономического развития России / Д.И. Менделеев. М.: Издательство социально-экономической литературы, 1960. С. 94-101.

18. Витте С.Ю. О ледоколе «Ермак» и намерении установить морской путь на Дальний Восток по северному побережью Сибири // Витте С.Ю. Избранные воспоминания, 1849-1911 гг. М.: Мысль, 1991. C. 657.

19. Менделеев Д.И. Заветные мысли. СПб.: Типолит. М.П. Фроловой, 1903-1905. 428 с.

20. Менделеев Д.И. К познанию России. СПб.: Изд. А.С. Суворина, 1906. 160 с.

Статья публикуется в рамках выполнения гранта Президента Российской Федерации для государственной поддержки молодых российских ученых - кандидатов наук (Конкурс - МК-2017) № MK-2889.2017.6.

\section{D.I. MENDELEEV ABOUT THE CULTURAL AND HISTORICAL TASKS OF RUSSIA IN THE EAST (C) 2018}

Suvorov Valery Vladimirovich, candidate of historical sciences, assistant of Philosophy, Humanities and Psychology Department Saratov State Medical University named after V.I. Razumovsky (Saratov, Russian Federation)

Abstract. At the turn of the XIX-XX centuries, the movement of Russia to the East became one of the topics discussed in domestic journalism and scientific thought. His views on this issue were also expressed by the outstanding scientist D.I. Mendeleev. In his works he stressed the historical necessity and inevitability of Russia's access to the Pacific Ocean, the importance of its foreign policy development in the Far East direction. Showing the cultural and civilizational distancing of Russia from the West, he focused on the presence of eastern features in it, but at the same time he noted its cultural and historical uniqueness. In Mendeleev's discourses, a departure from Eurocentrism in the assessments of the East and Russia can be traced. Speaking about the cultural and historical tasks of Russia, the scientist stressed that it was more important to maintain the «charm» of the name in the East than to imitate Western states, especially England. In Mendeleev's papers, special emphasis was made on the peaceful strengthening of Russia in Asia and a friendly attitude towards the Eastern peoples. An interesting feature of Mendeleev's reasoning is the motif of a fairy tale: on the one hand, it is a half-sketchy east, on the other, a fairy tale as the image of an ideal future for Russia.

Keywords: Dmitri Ivanovich Mendeleev; S.Yu. Witte; Russian empire; western countries; foreign policy; cultural and historical tasks of Russia in the East; Asia; Far East; Pacific Ocean; CERD; «Treasured thoughts»; China; Japan; Russo-Japanese War; eastern peoples; Eurasianism.

УДК 93/94

Статья поступила в редакцию 22.10.2017

\section{КУЛЬТУРНЫЕ ОСОБЕННОСТИ РОССИИ-ЕВРАЗИИ В КОНЦЕПЦИИ П.Н. САВИЦКОГО} (C) 2018

Быстрюков Владимир Юрьевич, кандидат исторических наук, доцент кафедры всеобщей истории, права и методики обучения Самарский государственный соџиально-педагогический университет (2. Самара, Российская Федераџия)

Аннотащия. Статья посвящена оценке П.Н. Савицким культурных особенностей России-Евразии. Как лидер евразийства, в своих работах он исходил из концептуальной установки движения - признания особой «евразийской» цивилизации. Влияние концепта Евразия имело ключевой характер для всей концепции 